\title{
ChemComm
}

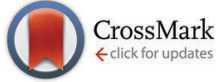

Cite this: Chem. Commun., 2016, 52,7842

Received 7th March 2016, Accepted 18th May 2016

DOI: $10.1039 / \mathrm{c} 6 \mathrm{cc0} 02020 \mathrm{~h}$

www.rsc.org/chemcomm

\section{Creating a hyperpolarised pseudo singlet state through polarisation transfer from parahydrogen under SABRE + +}

\author{
Alexandra M. Olaru, $\S^{a}$ Soumya S. Roy, $\S^{a}$ Lyrelle S. Lloyd, ${ }^{a}$ Steven Coombes, ${ }^{b}$ \\ Gary G. R. Green ${ }^{c}$ and Simon B. Duckett*a
}

\begin{abstract}
The creation of magnetic states that have long lifetimes has been the subject of intense investigation, in part because of their potential to survive the time taken to travel from the point of injection in a patient to the point where a clinically diagnostic MRI trace is collected. We show here that it is possible to harness the signal amplification by reversible exchange (SABRE) process to create such states in a hyperpolarised form that improves their detectability in seconds without the need for any chemical change by reference to the model substrate 2-aminothiazole. We achieve this by transferring Zeeman derived polarisation that is $\mathbf{1 5 0 0}$ times larger than that normally available at $400 \mathrm{MHz}$ with greater than $90 \%$ efficiency into the new state, which in this case has a 27 second lifetime.
\end{abstract}

As magnetic resonance detection, in the forms of NMR and MRI, is relatively insensitive, significant attention is currently placed on employing hyperpolarisation to create observable states that lie far from their normal Boltzmann derived intensity. The resulting signal enhancements offer opportunities to improve the diagnostic power of MRI through the collection of in vivo metabolite time course maps that link spatially resolved measurement to spectroscopic information. ${ }^{1}$ Such developments require the establishment of protocols to produce hyperpolarised contrast agents with magnetic state lifetimes that facilitate their detection after traveling to the region of clinical interest in the body. Longer magnetic state lifetimes would also be of benefit to NMR spectroscopy more generally as they would allow slower reactions to be followed directly by magnetisation transfer methods.

\footnotetext{
${ }^{a}$ Department of Chemistry, University of York, Heslington, York, YO10 5DD, UK. E-mail: simon.duckett@york.ac.uk; Tel: +44 1904322564

${ }^{b}$ AstraZeneca R\&D Pharmaceutical Development, Silk Road Business Park, Charter Way, Macclesfield, Cheshire, SK10 2NA, UK

${ }^{c}$ York Neuroimaging Centre, The Biocentre, York Science Park, Innovation Way, Heslington, York, YO10 5DD, UK

$\dagger$ Data created during this research are available by request from the University of York Data Catalogue http://dx.doi.org/10.15124/f0779356-a6f1-4c36-bac4-6fdf280ff6b2. \$ Electronic supplementary information (ESI) available: NMR measurements and characterisation. See DOI: 10.1039/c6cc02020h

$\S$ These authors contributed equally to the work of this manuscript.
}

Whilst hyperpolarised tracers have been produced by brute force methods, ${ }^{2}$ optical pumping ${ }^{3,4}$ and dynamic nuclear polarization, ${ }^{5}$ in this study, parahydrogen $\left(p-\mathrm{H}_{2}\right)$ derived hyperpolarisation is used as pioneered by Weitekamp, ${ }^{6}$ Eisenberg $^{7}$ and Bargon. ${ }^{8,9}$ The specific process utilised in this paper stems from a 2009 report that showed how magnetization transfer from $p-\mathrm{H}_{2}$ into a substrate could be achieved without the need for any chemical modification of the substrate. ${ }^{10}$ This process is termed SABRE (signal amplification by reversible exchange).

To date, SABRE has been applied to a range of molecules ${ }^{11-13}$ including pyridine, ${ }^{14}$ nicotinamide ${ }^{15}$ and quinoline, ${ }^{16}$ and a range of nuclei. ${ }^{17-20}$ A large number of variables affect the efficiency of $\mathrm{SABRE}^{21,22}$ which include relaxation, temperature and concentration of the catalyst, substrate and $p-\mathrm{H}_{2}$. However, as we are dealing with a hyperpolarisation process rather than a chemical transformation, the strength of the magnetic field experienced during polarisation transfer is also important, as is the number of protons and spin topology of the analytes that are to receive hyperpolarisation. ${ }^{9}$

Optimisation of the SABRE process is further complicated by the array of magnetic states that are generated, which include longitudinal single-spin (Zeeman polarisation), two-spin and higher order terms. ${ }^{23,24}$ These states will be characterised by their own unique relaxation times and readout strategies. We show here that it is possible to store this highly polarized Zeeman state in longer lived singlet (LLS) order for subsequent detection. In this context, singlet states are non-magnetic spin isomers of a coupled spin-1/2 pair which are immune to external dipolar coupling and hence often much longer lived $\left(\mathrm{T}_{\mathrm{LLS}}\right)$ than a normal $\mathrm{T}_{1}$ lifetime. ${ }^{25,26}$ 2-Aminothiazole (atz) of Fig. 1 is used in this model study.

Its heterocyclic amine core features heavily in biocides, fungicides and dyes, and recently it has been used as a building block in drugs that show wide ranging activity. ${ }^{27-29}$ This makes atz an attractive candidate for hyperpolarisation because the improved sensitivity may allow it to act as a small molecule probe for metabolic studies. ${ }^{30,31}$ 2-Aminothiazole contains four protons but because these studies are carried out in $d_{4}$-methanol 


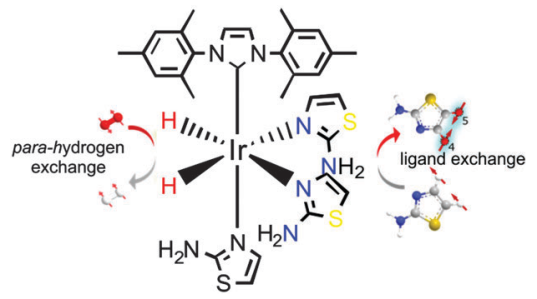

Fig. 1 SABRE magnetisation transfer concept based on 3a where ligand exchange leads to hyperpolarised atz.

those of the $\mathrm{NH}_{2}$ group are removed by hydrogen-deuterium exchange. This process leaves behind the two mutually coupled and magnetically isolated $\mathrm{H}-4$ and $\mathrm{H}-5$ protons that are connected by a ${ }^{3} J_{\mathrm{HH}}$ coupling of $3.8 \mathrm{~Hz}$ and separated by $160.8 \mathrm{~Hz}$ at $400 \mathrm{MHz}$. Whilst these resonances lie relatively far apart in frequency terms, thereby limiting the lifetime of any shared long-lived state, atz represents a simple test system that builds from the pioneering work of Levitt and is suitable for SABRE. ${ }^{25,26}$

Since atz possesses two potential metal-ligand binding sites we first set out to characterise the product formed upon reaction with $\operatorname{IrCl}(\mathrm{COD})(\mathrm{NHC})(\mathbf{1})$ where the N-heterocyclic carbene (NHC) is derived from 1,3-bis(2,4,6-trimethylphenyl)-imidazolium (1a), 1,3-bis(2,4,6-trimethylphenyl)-4,5-dihydroimidazolium (1b) and 1,3-bis(2,6-diisopropylphenyl)imidazolium (1c) and COD is cyclooctadiene. The formation of $[\operatorname{Ir}(\mathrm{COD})(\mathrm{NHC})(\mathrm{atz})] \mathrm{Cl}$ (2) proceeds over 5 minutes at room temperature with the binding of atz taking place through the thiazole-ring-nitrogen. When $\mathrm{H}_{2}$ was added to these solutions, the rapid conversion of 2 into $\left[\operatorname{Ir}(\mathrm{H})_{2}(\mathrm{NHC})(\mathbf{a t z})_{3}\right] \mathrm{Cl}$ (cis-cis-3) occurs where atz binds similarly. The characterisation of these complexes is described in the ESI.

The hyperpolarisation of atz under SABRE was then explored in a $5 \mathrm{~mm}$ NMR tube containing 3 bar $p-\mathrm{H}_{2}$ pressure. When a $5 \mathrm{mM}$ solution of 3 was examined in the presence of a 17 -fold excess of atz, its H-4 signal exhibited $199 \pm 12-, 386 \pm 20-$ and $209 \pm 21$-fold enhancements for $\mathbf{3 a}, \mathbf{3 b}$ and $\mathbf{3} \mathbf{c}$ respectively after transfer at $60 \mathrm{G}$. These values changed to $386 \pm 82-, 432 \pm 38$ and $108 \pm 12$-fold when the atz excess was reduced to 2-fold. These data show that $\mathbf{3 b}$ is the most suitable catalyst for magnetisation transfer under SABRE into atz. This observation is supported by the measurement of the build-up rate constant of atz in solution after dissociation from the site trans to hydride of $3 \mathrm{a}$ which proved to be $2.04 \pm 0.01 \mathrm{~s}^{-1}$ at $300 \mathrm{~K}$ which is 15 times slower than the corresponding rate of pyridine build-up in solution from $\left[\operatorname{Ir}(\mathrm{IMes})(\mathrm{H})_{2}(\mathrm{py})_{3}\right] \mathrm{Cl}(4)$, a complex that is know to yield very good pyridine proton signal enhancements under SABRE. The corresponding rate of build-up in $\mathbf{3 b}$ was $4.70 \pm 0.05 \mathrm{~s}^{-1}$ under similar conditions and suggests that it's greater SABRE efficiency stems from faster ligand exchange.

The corresponding activation parameters for atz build-up in solution and $\mathrm{H}_{2}$ loss in 3 are presented in Table 1. These data suggest that the binding energy of atz in $\mathbf{3 a}$ and $\mathbf{3 b}$ is lower than that of pyridine in $\mathbf{4}$ for which the site trans to hydride has a $\Delta H_{\text {(build-up) }}^{*}$ value of $95 \pm 1 \mathrm{~kJ} \mathrm{~mol}^{-1}$. Given that the reported $\mathrm{p} K_{\mathrm{a}}$ of pyridine is 5.17 whilst that of atz is 5.39, it is likely that steric effects act to lengthen the atz bond in the ground state and thereby reducing the subsequent entropy gain of ligand release in order to account for these values.

As we are equilibrating spin-polarisation between hydride and ligand sites during SABRE, we also studied the effect of $3 \mathbf{a}$ and $\mathbf{3 b}$ on the relaxation times of the states $\mathrm{I}_{z}(\mathrm{H}-4), \mathrm{S}_{z}(\mathrm{H}-5)$ and the more unusual singlet spin order $\left(\mathrm{T}_{\mathrm{LLS}}, \mathrm{I} \cdot \mathrm{S}\right)$ of atz as shown in Table 2; these polarisation data were recorded in an automated flow mode as described previously. ${ }^{15}$ The pulse sequences detailed in the SI were used to make these measurements. The corresponding three relaxation times for free atz are 23, 26 and 27 seconds respectively. Based on the relaxation data of Table 2 it is clear that the presence of 3 acts to redistribute the magnetisation between the coupled spins through the SABRE effect. This change manifests itself in a $65 \%$ reduction in the $\mathrm{T}_{1}$ value of $\mathrm{H}-4$ when compared to that of the free material in the presence of 3a; this is much larger than the H-5 site fall of $29 \%$. This change dovetails with the fact that proton $\mathrm{H}-4$ is next to the binding site and experiences the strongest hydride ligand interaction.

In order to harness these effects to probe the resulting singlet spin order, a single scan ${ }^{1} \mathrm{H}$ NMR spectrum of atz was collected for comparison purposes that employs thermally equilibrated polarisation at $400 \mathrm{MHz}$ as shown in Fig. 2(a). Fig. 2(b) shows the resulting NMR trace that was produced upon observation of the $\mathrm{S}_{0}$ state after a one second spin-lock and its creation from the thermally polarized state by the method of Levitt. ${ }^{25}$ This state proved to have a lifetime of 27 seconds in the absence of oxygen and catalyst but was reduced in the presence of $3 \mathbf{a}$ and $\mathrm{H}_{2}$ as detailed in Table 2, although with a 20 -fold ligand excess and $\mathbf{3 b}$ there is little effect. This confirms that catalyst design can be used not only to optimise the level of SABRE, but also to control its effect on the relaxation characteristics of the substrate. $^{32}$

We then prepared the corresponding hyperpolarised Zeeman spin order in a sealed NMR tube through the action of SABRE via 3a as detailed in Fig. 2(c) for subsequent conversion into the $\mathrm{S}_{0}$ state. We used the sealed tube because it produces higher

Table 1 Activation parameters for specified exchange processes in $\mathbf{3 a}$ and $\mathbf{3 b}$

\begin{tabular}{|c|c|c|c|c|}
\hline \multirow[b]{2}{*}{ Ligand exchange process } & \multicolumn{2}{|l|}{$\underline{\mathrm{H}_{2}}$ loss from } & \multicolumn{2}{|c|}{ Free atz build-up } \\
\hline & $3 \mathbf{a}$ & $3 \mathbf{b}$ & $3 \mathbf{a}$ & $3 \mathbf{b}$ \\
\hline Raw rate $\mathrm{s}^{-1}(300 \mathrm{~K})$ & $0.86 \pm 0.01$ & $3.41 \pm 0.02$ & $2.04 \pm 0.01$ & $4.70 \pm 0.05$ \\
\hline$\Delta H^{\ddagger} / \mathrm{kJ} \mathrm{mol}^{-1}$ & $83 \pm 3$ & $87 \pm 2$ & $86 \pm 3$ & $77 \pm 3$ \\
\hline$\Delta S^{\ddagger} / \mathrm{J} \mathrm{K}^{-1} \mathrm{~mol}^{-1}$ & $37 \pm 8$ & $62 \pm 8$ & $54 \pm 11$ & $31 \pm 10$ \\
\hline$\Delta G_{300}^{\ddagger} / \mathrm{kJ} \mathrm{mol}^{-1}$ & $72.2 \pm 0.1$ & $68.8 \pm 0.1$ & $70.1 \pm 0.1$ & $67.9 \pm 0.1$ \\
\hline
\end{tabular}


Table 2 Substrate to catalyst (3) ratio, signal gain and relaxation data associated with protons $\mathrm{H}-4$ and $\mathrm{H}-5$ of atz in $d_{4}$-methanol, determined using an automated polariser ${ }^{15}$ with $\mathbf{3 a}$ and $\mathbf{3 b}$

\begin{tabular}{|c|c|c|c|c|c|}
\hline \multirow{2}{*}{$\frac{\text { Complex }}{3: \text { atz ratio }}$} & & \multicolumn{2}{|l|}{$3 a$} & \multicolumn{2}{|l|}{$3 \mathbf{b}$} \\
\hline & & $1: 2$ & $1: 17$ & $1: 2$ & $1: 17$ \\
\hline Signal gain & $\begin{array}{l}\mathrm{H}-4 \\
\mathrm{H}-5\end{array}$ & $\begin{array}{l}-456 \\
-693\end{array}$ & $\begin{array}{l}-113 \\
-127\end{array}$ & $\begin{array}{l}-441 \\
-547\end{array}$ & $\begin{array}{l}-356 \\
-425\end{array}$ \\
\hline $\mathrm{T}_{1}(\mathrm{~s})$ & $\begin{array}{l}\mathrm{H}-4 \\
\mathrm{H}-5\end{array}$ & $\begin{array}{l}10.0 \pm 0.4 \\
18.5 \pm 0.6\end{array}$ & $\begin{array}{l}15.1 \pm 0.3 \\
22.9 \pm 0.3\end{array}$ & $\begin{array}{l}12.2 \pm 0.5 \\
23.7 \pm 0.8\end{array}$ & $\begin{array}{l}16.2 \pm 0.6 \\
25.0 \pm 0.8\end{array}$ \\
\hline $\mathrm{T}_{\text {LLS }}(\mathrm{s})$ & & $16.5 \pm 3.2$ & $18.3 \pm 2.8$ & $13.3 \pm 2.6$ & $26.8 \pm 3.9$ \\
\hline
\end{tabular}

(a)

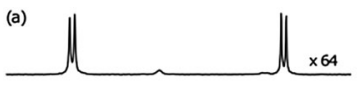

(b)

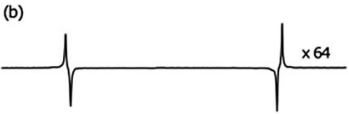

(c)

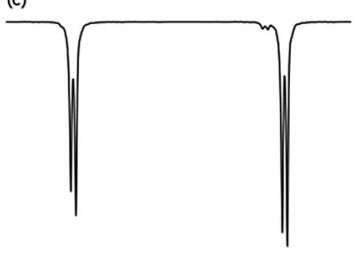

$\begin{array}{llllll}7.0 & 6.9 & 6.8 & 6.7 & 6.6 & \mathrm{ppm}\end{array}$

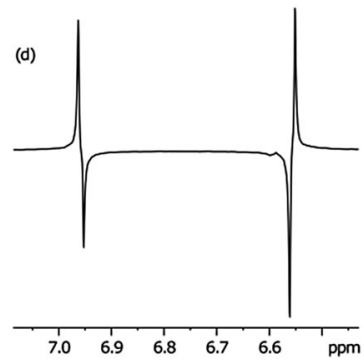

Fig. 2 Plots showing the ${ }^{1} \mathrm{H}$ NMR signals of atz at $400 \mathrm{MHz}$ for: (a) a single shot thermally equilibrated ${ }^{1} \mathrm{H}$ NMR spectrum, (b) a $\mathrm{S}_{0}$ derived spectrum of atz that is created and examined $1 \mathrm{~s}$ later by the method of Levitt, (c) the corresponding 3a derived SABRE hyperpolarised atz spectrum and (d) the $S_{0}$ state $1 \mathrm{~s}$ after it was created through SABRE and a spin-lock. (Traces in (a) and (b) have a $64 \times$ vertical expansion relative to (c) and (d) respectively).

levels of hyperpolarisation than the flow system. The pulse sequence employed a $1 \mathrm{kHz}$ low power spin-lock during state preservation. As revealed in Fig. 2(d) a dramatic increase in the level of $S_{0}$ spin order results from this process. Based on these data the relayed SABRE transfer occurs with $90 \%$ efficiency. Fig. 3 reveals that significant hyperpolarised- $\mathrm{S}_{0}$ derived magnetisation can be seen, even after 60 seconds.

In this report we have demonstrated how SABRE derived hyperpolarisation can be readily used to create long-lived $S_{0}$ magnetisation by reference to 2-aminothiazole. The efficiency of this process was optimised by varying the SABRE catalyst such that an initial $4.5 \%$ level of Zeeman hyperpolarisation (1500-fold enhancement) was harnessed to create the longerlived $\mathrm{S}_{0}$ magnetisation in 2-aminothiazole. This process reflects a simple and efficient route to rapidly create hyperpolarised long-lived states in a matter of seconds that should be amenable for future in vivo measurement.

We thank the Wellcome Trust (092506 and 098335) and Astra Zeneca (case award LSL) for funding. We are also grateful to discussions with Ryan Mewis, Bruker BioSpin (Joost Lohman, Jean-Max Tyburn, Patrick Krencker and David Kilgour) and Richard. J. Lewis, Michael Bernstein and Christopher J. Sleigh of Astra-Zeneca.
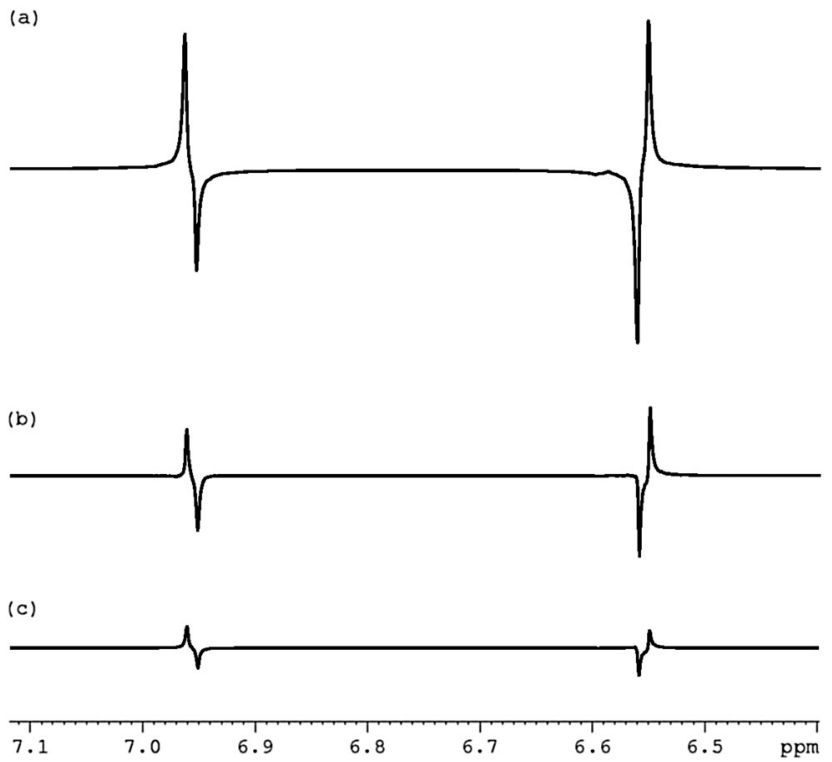

Fig. $3{ }^{1} \mathrm{H}$ NMR traces showing the decay in the SABRE driven singlet $\left(\mathrm{S}_{0}\right)$ magnetisation over spin-lock times of: (a) $1 \mathrm{~s}$, (b) $30 \mathrm{~s}$ and (c) $60 \mathrm{~s}$.

\section{Notes and references}

1 K. Golman, R. in't Zandt, M. Lerche, R. Pehrson and J. H. ArdenkjaerLarsen, Cancer Res., 2006, 66, 10855-10860.

2 M. L. Hirsch, N. Kalechofsky, A. Belzer, M. Rosay and J. G. Kempf, J. Am. Chem. Soc., 2015, 137, 8428-8434.

3 A. M. Oros and N. J. Shah, Phys. Med. Biol., 2004, 49, R105-R153.

4 D. M. L. Lilburn, G. E. Pavlovskaya and T. Meersmann, J. Magn. Reson., 2013, 229, 173-186.

5 J. H. Ardenkjær-Larsen, B. Fridlund, A. Gram, G. Hansson, L. Hansson, M. H. Lerche, R. Servin, M. Thaning and K. Golman, Proc. Natl. Acad. Sci. U. S. A., 2003, 100, 10158-10163.

6 C. R. Bowers and D. P. Weitekamp, J. Am. Chem. Soc., 1987, 109, 5541-5542.

7 T. C. Eisenschmid, R. U. Kirss, P. P. Deutsch, S. I. Hommeltoft, R. Eisenberg, J. Bargon, R. G. Lawler and A. L. Balch, J. Am. Chem. Soc., 1987, 109, 8089-8091.

8 J. Natterer and J. Bargon, Prog. Nucl. Magn. Reson. Spectrosc., 1997, 31, 293-315.

9 R. A. Green, R. W. Adams, S. B. Duckett, R. E. Mewis, D. C. Williamson and G. G. R. Green, Prog. Nucl. Magn. Reson. Spectrosc., 2012, 67, 1-48.

10 R. W. Adams, J. A. Aguilar, K. D. Atkinson, M. J. Cowley, P. I. P. Elliott, S. B. Duckett, G. G. R. Green, I. G. Khazal, J. Lopez-Serrano and D. C. Williamson, Science, 2009, 323, 1708-1711.

11 E. B. Duecker, L. T. Kuhn, K. Muennemann and C. Griesinger, J. Magn. Reson., 2012, 214, 159-165.

12 M. L. Truong, F. Shi, P. He, B. Yuan, K. N. Plunkett, A. M. Coffey, R. V. Shchepin, D. A. Barskiy, K. V. Kovtunov, I. V. Koptyug, K. W. Waddell, B. M. Goodson and E. Y. Chekmenev, J. Phys. Chem. B, 2014, 118, 13882-13889.

13 H. Zeng, J. Xu, J. Gillen, M. T. McMahon, D. Artemov, J.-M. Tyburn, J. A. B. Lohman, R. E. Mewis, K. D. Atkinson, G. G. R. Green, S. B. Duckett and P. C. M. van Zijl, J. Magn. Reson., 2013, 237, 73-78.

14 K. D. Atkinson, M. J. Cowley, P. I. P. Elliott, S. B. Duckett, G. G. R. Green, J. Lopez-Serrano and A. C. Whitwood, J. Am. Chem. Soc., 2009, 131, 13362-13368.

15 R. E. Mewis, K. D. Atkinson, M. J. Cowley, S. B. Duckett, G. G. R. Green, R. A. Green, L. A. R. Highton, D. Kilgour, L. S. Lloyd, J. A. B. Lohman and D. C. Williamson, Magn. Reson. Chem., 2014, 52, 358-369.

16 L. S. Lloyd, R. W. Adams, M. Bernstein, S. Coombes, S. B. Duckett, G. G. R. Green, R. J. Lewis, R. E. Mewis and C. J. Sleigh, J. Am. Chem. Soc., 2012, 134, 12904-12907.

17 V. V. Zhivonitko, I. V. Skovpin and I. V. Koptyug, Chem. Commun., 2015, 51, 2506-2509. 
18 M. J. Burns, P. J. Rayner, G. G. R. Green, L. A. R. Highton, R. E. Mewis and S. B. Duckett, J. Phys. Chem. B, 2015, 119, 5020-5027.

19 M. L. Truong, T. Theis, A. M. Coffey, R. V. Shchepin, K. W. Waddell, F. Shi, B. M. Goodson, W. S. Warren and E. Y. Chekmenev, J. Phys. Chem. C, 2015, 119, 8786-8797.

20 R. E. Mewis, R. A. Green, M. C. R. Cockett, M. J. Cowley, S. B. Duckett, G. G. R. Green, R. O. John, P. J. Rayner and D. C. Williamson, J. Phys. Chem. B, 2015, 119, 1416-1424.

21 B. J. A. van Weerdenburg, S. Gloeggler, N. Eshuis, A. H. J. Engwerda, J. M. M. Smits, R. de Gelder, S. Appelt, S. S. Wymenga, M. Tessari, M. C. Feiters, B. Blümich and F. P. J. T. Rutjes, Chem. Commun., 2013, 49, 7388-7390.

22 L. S. Lloyd, A. Asghar, M. J. Burns, A. Charlton, S. Coombes, M. J. Cowley, G. J. Dear, S. B. Duckett, G. R. Genov, G. G. R. Green, L. A. R. Highton, A. J. J. Hooper, M. Khan, I. G. Khazal, R. J. Lewis, R. E. Mewis, A. D. Roberts and A. J. Ruddlesden, Catal. Sci. Technol., 2014, 4, 3544-3554.

23 R. W. Adams, S. B. Duckett, R. A. Green, D. C. Williamson and G. G. R. Green, J. Chem. Phys., 2009, 131, 194505.

24 A. N. Pravdivtsev, A. V. Yurkovskaya, H.-M. Vieth and K. L. Ivanov, Phys. Chem. Chem. Phys., 2014, 16, 24672-24675.
25 M. Carravetta and M. H. Levitt, J. Am. Chem. Soc., 2004, 126, 6228-6229.

26 M. H. Levitt, in Annu. Rev. Phys. Chem., ed. M. A. Johnson and T. J. Martinez, Annual Reviews, Palo Alto, 2012, vol. 63, pp. 89-105.

27 A. S. Kalgutkar, I. Gardner, R. S. Obach, C. L. Shaffer, E. Callegari, K. R. Henne, A. E. Mutlib, D. K. Dalvie, J. S. Lee, Y. Nakai, J. P. O'Donnell, J. Boer and S. P. Harriman, Curr. Drug Metab., 2005, 6, 161-225.

28 I. Lagoja, C. Pannecouque, G. Griffioen, S. Wera, V. M. Rojasdelaparra and A. Van Aerschot, Eur. J. Pharm. Sci., 2011, 43, 386-392.

29 M. Pieroni, B. J. Wan, S. H. Cho, S. G. Franzblau and G. Costantino, Eur. J. Med. Chem., 2014, 72, 26-34.

$30 \mathrm{~J}$. Kurhanewicz, D. B. Vigneron, K. Brindle, E. Y. Chekmenev, A. Comment, C. H. Cunningham, R. J. DeBerardinis, G. G. Green, M. O. Leach, S. S. Rajan, R. R. Rizi, B. D. Ross, W. S. Warren and C. R. Malloy, Neoplasia, 2011, 13, 81-97.

31 T. L. Davis, K. K. Kwong, R. M. Weisskoff and B. R. Rosen, Proc. Natl. Acad. Sci. U. S. A., 1998, 95, 1834-1839.

32 G. Stevanato, J. T. Hill-Cousins, P. Hakansson, S. S. Roy, L. J. Brown, R. C. D. Brown, G. Pileio and M. H. Levitt, Angew. Chem., Int. Ed., 2015, 54, 3740-3743. 